\title{
Use of Ultrasound to Enhance Flotation Performance: Flotation Cleaning of Oil Shale after Ultrasonic Pre-Treatment
}

\author{
N. Emre Altun ${ }^{1}$, Jiann-Yang Hwang ${ }^{2}$, C. Hicyilmaz ${ }^{1}$ \\ ${ }^{1}$ Middle East Technical University, Mining Engineering Department, \\ Ankara, Turkey \\ ealtun@metu.edu.tr \\ ${ }^{2}$ Michigan Technological University, Materials Science and Engineering, \\ Houghton, MI, USA
}

\begin{abstract}
This study aims at determining the contribution of ultrasonication to conventional flotation. In this regard, enhancing the performance of flotation cleaning of an oil shale sample was attempted using ultrasonic pre-treatment. The use of the excitation effect through ultrasonication was investigated towards fine and ultra-fine ash making-inorganic particles that are clogged in pores/voids or are attached as coatings on surfaces of larger entities. Ultrasonic pre-treatment was applied prior to flotation at a range of ultrasonic power levels and for different durations of ultrasonication. This pre-treatment proved to be useful in improving the extent of ash rejection and producing a cleaner oil shale concenrate at remarkable combustible recoveries. Conventional flotation cleaning (without ultrasonic pretreatment) could reduce the ash content of the cleaned oil shale from $34.76 \%$ to 16.82 . Ultrasonic-aided flotation resulted in further decrease in ash to $11.82 \%$ at $82.66 \%$ combustible recovery. Comparative XRD and SEM analyses showed that inorganic particles in the pores/voids or attached to the surfaces of larger particles were effectively removed after ultrasonic pre-treatment. This has significantly improved the liberation between organic and inorganic entities, leading to a more effective separation process through fllotation.
\end{abstract}

Keywords: Ultrasound, Flotation, Oil Shale.

\section{Introduction}

Ultrasound is a three-dimensional pressure wave consisting of subsequent compression and rarefaction cycles. Ultrasonic waves only require a liquid phase to transmit energy [1] where ultrasonic vibrations activate or accelerate many processes in liquid systems. The alternating behavior of these cycles are known as cavitation. Cavitation imposes significant effect on any solid phase within the liquid [2]. Use of this feature for cleaning of metal surfaces, in sedimentation and dewatering, waste water treatment and metals precipitation have been reported [3-5]. Flotation is one of the conventional methods for coal preparation and cleaning of solid fuels. However, the inherent ash or insufficient liberation might lead to ineffective rejection of ash making constituents by flotation. Ultrasonic waves could be used to enhance or to aid flotation. The goal in this study is to enhance effectiveness of flotation with the aid of ultrasonication. In this respect, it was investigated whether the extent of improvement in the fuel characteristics of an oil shale sample could be enhanced by ultrasonic pretreatment prior to flotation. In this context, oil shale was treated with ultrasonication at varying power levels and for a range of ultrasonication periods and then subjected to flotation cleaning at optimized conditions determined in the previous phase of this research. The effectiveness of flotation with and without ultrasonication was comparatively assessed through X-Ray Diffraction analysis and using Scanning Electron Microscopy.

\section{Materials and Methods}

This study focuses on the possible use of ultrasonication for enhancing the effectiveness of flotation. An oil shale sample from Turkey, that consists of finely distributed inorganic, ash making constituents within the cavities and pores of organic-rich sections, is used for the tests. This specific feature adversely affects the effectiveness of flotation cleaning. Also, in Turkey, oil shales are either separated as waste during coal exploitation or left in place non-extracted. If this study can reveal the usefulness of ultrasonic-aided flotation in the separation of ash making constituents, it can contribute to prospective strategies for utilization of oil shales in Turkey as an alternative to low-quality lignites. The fundamental fuel characteristics 
of the raw oil shale are given in Table 1. The surface, powder and morphological characteristics of the sample were obtained using X-Ray Diffraction (XRD) and Scanning Electron Microscopy (SEM). Ultrasonic treatment of the oil shale prior to flotation was conducted using a Sonics \& Materials Vibra Cell, open probe ultrasonic instrument. Ultrasonication power is $250 \mathrm{~W}$, allowing power adjustment in a range of 20-100\%. Duration of ultrasonication can also be adjusted using the timer knob on the instrument.

For ultrasonic pre-treatment, oil shale sample and water was mixed thoroughly in the flotation cell. Ultrasonication probe was then immersed into the pulp and ultrasonication was commenced. Ultrasonication was varied by adjusting the ultrasonic power level and duration of ultrasonication. As the initial phase, the effect of ultrasonic power level on the extent of cleaning was determined. The ultrasonic power level was changed in a range of $20-100 \%$ with $10 \%$ increments. These tests were conducted using a constant ultrasonication period of 5 minutes. Following the identification of the most favorable ultrasonication power level, the influence of ultrasonication period was investigated by pre-treatments for 5 to 30 minutes, with 5 minutes increments. Immediately after ultrasonic pre-treatment, the samples were subjected to batch flotation tests in a lab-scale Wedag flotation machine, using a $650 \mathrm{ml}$ flotation cell and optimum flotation conditions found in the previous phase of this work that solely aimed at finding out the most favorable flotation parameters for this oil shale sample. These conditions are presented in Table 2. Cleaned oil shale and reject products were subjected to ash analysis. Using the ash analysis results, combustible recovery values were computed for each flotation test as a measure of the effectiveness of cleaning. The following equation was used to calculate the combustible recovery values $\left(\mathrm{R}_{\mathrm{com}}\right)$ :

$$
\mathrm{R}_{\text {com }} \%=\frac{\text { Product Weight } \% \text { x }(100-\text { Product Ash \% })}{(100-\text { Feed Ash \% })}
$$

Table 1: Fundamental Fuel Characteristics of the Raw Oil Shale Sample (as-received).

\begin{tabular}{|l|r|l|r|}
\hline \multicolumn{2}{|c|}{ Proximate Analysis } & \multicolumn{2}{|c|}{ Ultimate Analysis } \\
\hline Moisture, \% & 5.40 & $\mathrm{C}, \%$ & 54.30 \\
\hline Volatile Matter, \% & 38.40 & $\mathrm{H}, \%$ & 8.80 \\
\hline Fixed Carbon, \% & 21.40 & $\mathrm{~N}, \%$ & 1.60 \\
\hline Ash, \% & 34.80 & $\mathrm{O}, \%$ & 32.20 \\
\hline \multicolumn{2}{|c|}{} & $\mathrm{S}, \%$ (Total) & 3.10 \\
\hline Calorific Value, kcal/kg & 4312 & & \\
\hline
\end{tabular}

Table 2: Favorable Flotation Conditions for Cleaning the Oil Shale (no ultrasonic pre-treatment) [6].

\begin{tabular}{|l|r|}
\hline Flotation Method & Reverse \\
\hline Promoter & Flotigam CA / 800 g/ton \\
\hline Frother & Aerofroth $65 / 27.5 \mathrm{~g} / \mathrm{ton}$ \\
\hline Pulp pH & 7.3 (natural pH) \\
\hline Pulp Density & $10 \%$ by wt. \\
\hline F $_{80}$ & $-100 \mu \mathrm{m}$ \\
\hline Conditioning Time & 15 minutes \\
\hline Flotation Time & 4.5 minutes \\
\hline
\end{tabular}




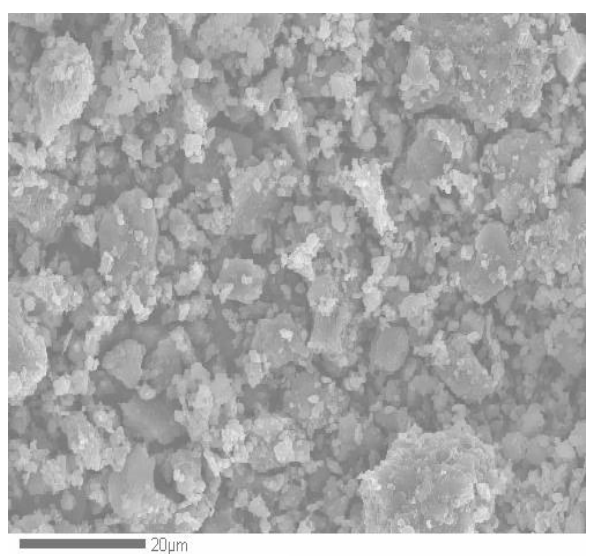

(a)

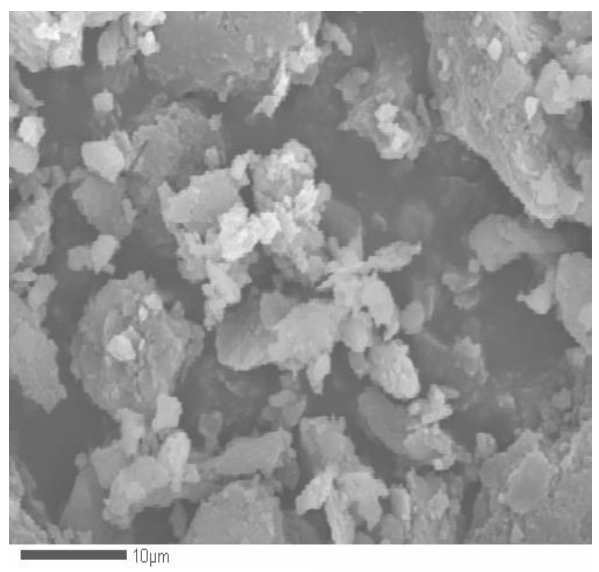

(c)

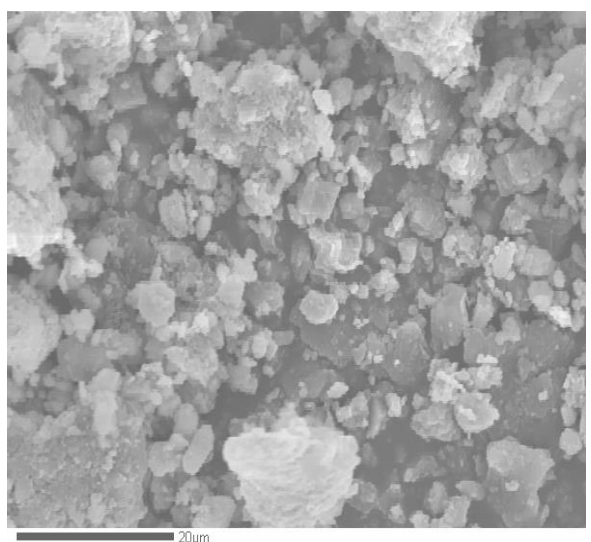

(b)

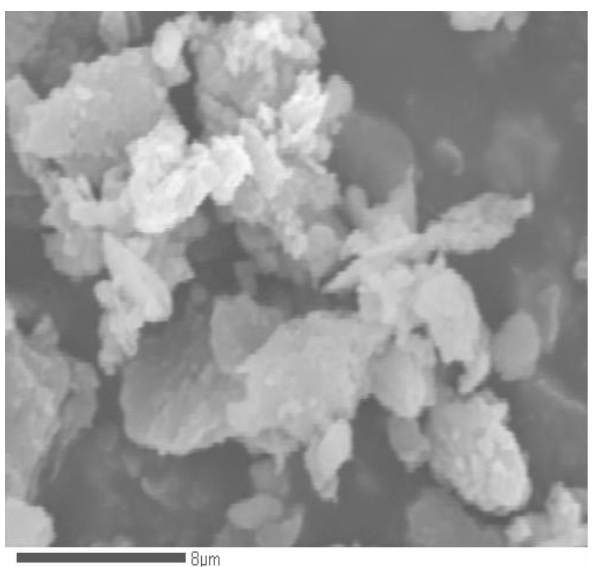

(d)

Fig. 1: Typical SEM Images of Raw Oil Shale.

\section{Results and Discussion}

\subsection{Characteristics of Oil Shale}

Some typical SEM images of the raw oil shale sample are presented in Figure 1. Mineralogical analysis by microscobic investigations on thin sections showed that the inorganic gangue mainly consisted of carbonates, i.e. calcite and dolomite. As revealed by the SEM images, the carbonaceous gangue occurs mostly as finely disseminated entities. The size of the carbonate particles is 5 to $50 \mu \mathrm{m}$. Pyrite is another remarkable inorganic component and occurs in 5-15 $\mu \mathrm{m}$ size. Pyrite is mainly seen in association with larger particles. Other notable inorganic constituents were quartz $(20-30 \mu \mathrm{m})$ and opal (80$120 \mu \mathrm{m})$. XRD pattern of the raw oil shale is shown in Figure 2.a. In confirmation with the mineralogical analysis, XRD pattern confirmed that calcite is the most abundant carbonaceous mineral and inorganic constituent in the sample. The specific section between $5-29^{0}$ revealed that the organic content of the sample is mainly in amorphous form. In the FTIR spectrum several characteristic functional groups and peaks were detected (Figure 3). FTIR spectrum showed that the given oil shale is an organic rich fossil fuel of highly humic character. Several strong and broad functional bands pointing to the presence of hydroxyl, carboxyl and carbonyl groups are the indicators of the humic character. In addition, the organic content of the sample is revealed by the aliphatic $\mathrm{CH}_{3}$ and $\mathrm{CH}_{2}$ bands in the form of intense, distinctive peaks, the relatively broad aromatic band at $1625 \mathrm{~cm}^{-1}$ and the aromatic bands between $850-675 \mathrm{~cm}^{-1}$. 


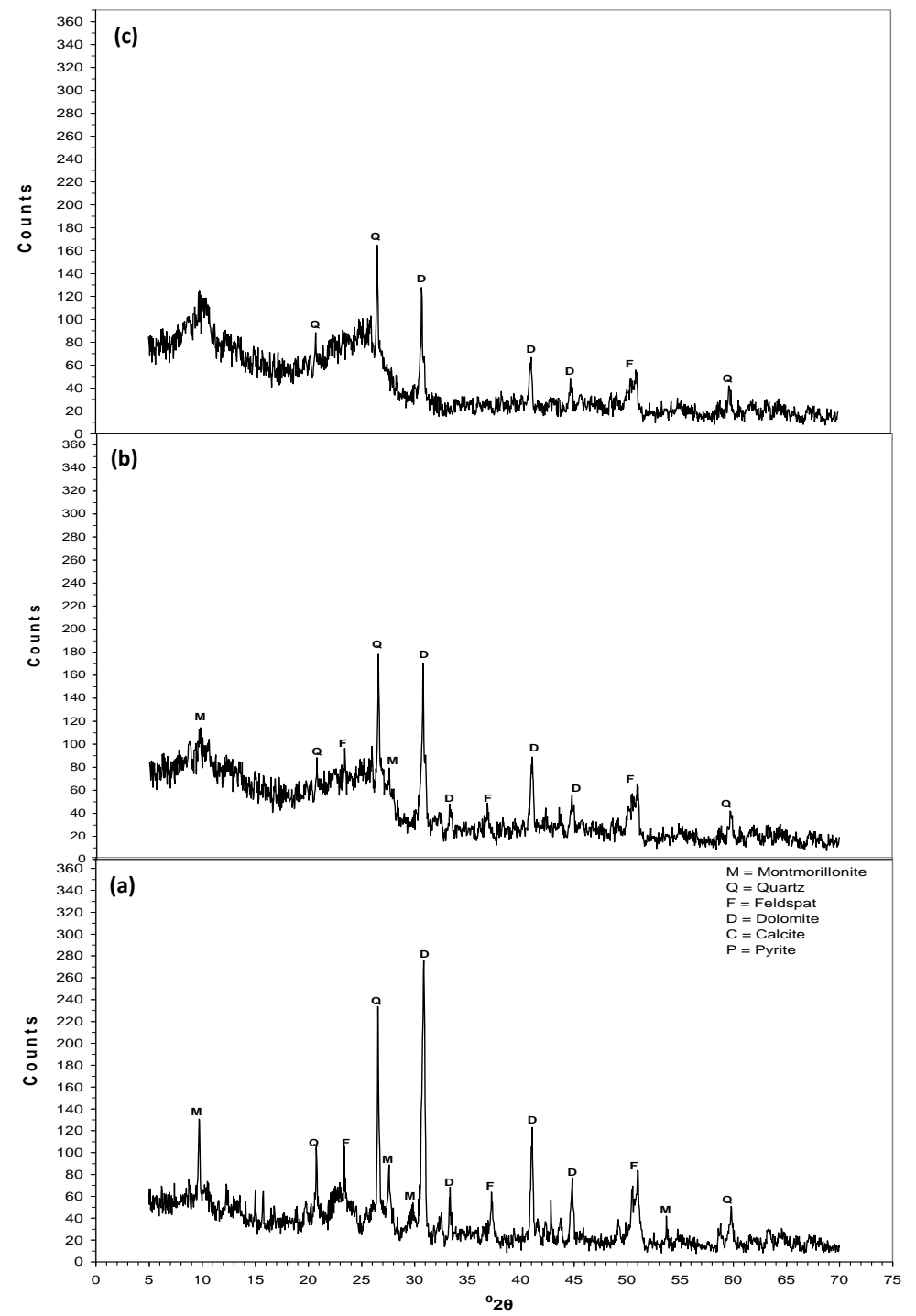

Fig. 2: XRD Pattern of (a) Raw Oil Shale, (b) Optimum Flotation Concentrate, (c) Flotation Concentrate after Ultrasonic Pre-Treatment of Oil Shale.

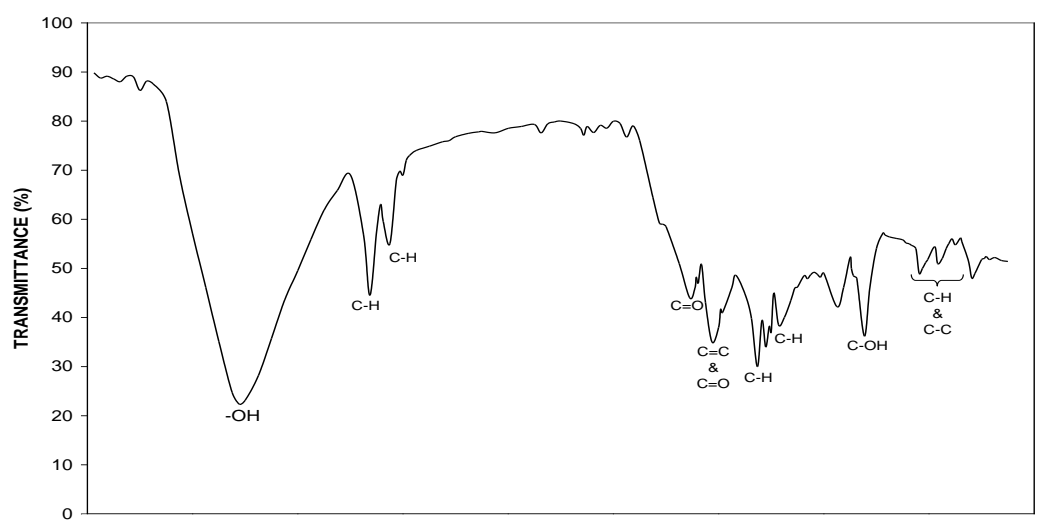

Fig. 3: FTIR Spectrum of Raw Oil Shale. 


\subsection{Ultrasonic-Aided Flotation of Oil Shale}

After ultrasonic pre-treatment, flotation tests were done at the favorable conditions found in the previous phases of this research. The favorable conditions were actually the optimum conditions determined through statistical modeling of several operational parameters and parameter levels. The details can be found elsewhere [6]. The flotation conditions that provide the most favorable ash rejection with a remarkable extent of combustible recovery are presented in Table 2 . Reverse flotation was found to be more effective than direct flotation for this oil shale, i.e. the inorganic constituents were rendered hydrophobic (rather than the organic constituents) and separated as the froth product. For the flotation of inorganic entities an amine acetate type collector, Flotigam CA, was found as the most effective collector. At the favorable flotation conditions, the ash of the oil shale was reduced from $34.76 \%$ to $16.81 \%$ at $84.10 \%$ combustible recovery.

Flotation results after ultrasonic pre-treatment of the oil shale at different power levels are given in Figure 4 . At 20 and $30 \%$ power levels, ultrasonic pre-treatment resulted in limited decreases in the ash content of the cleaned oil shale product (ash decreased from 16.82 to $16.40 \%$ at $30 \%$ ultrasonic power). The combustible recovery also decreased from 84.10 to $82.29 \%$. From 30 to $50 \%$ power, the ash further decreased to $14.96 \%$ with $<1 \%$ decrease in combustible recovery (Figure 4). Above $50 \%$ ultrasonication power, the ash content of the cleaned oil shale showed a tendency to increase until full power level $(100 \%)$. The ash content reached $18.62 \%$ at this level. Thus, it was seen that $50 \%$ ultrasonication power was the most effective level in terms of ash rejection at a remarkable combustible recovery (81.57\%, Figure 4$)$. The tests to identify the favorable ultrasonic pre-treatment duration were, therefore, conducted at $50 \%$ ultrasonic power level. Flotation results after ultrasonic pre-treatment of oil shale for varying ultrasonication durations are shown in Figure 5. From 0 to 15 minutes, the ash content of the cleaned oil shale decreased from 16.82 to $11.82 \%$ with a slight decrease in combustible recovery $(84.10$ to $82.66 \%$ ). Above 15 minutes of ultrasonication, however, increases were recorded in ash. The ash content of the cleaned oil shale product was almost doubled to $22.86 \%$ after 30 minutes of ultrasonication.

Overall, it is seen that ultrasonic pre-treatment favors the flotation cleaning of oil shale up to $50 \%$ ulrasonic power level and 15 minutes pre-treatment period. The positive influence of ultrasonication up to these levels were attributed to the enhancement of the separation process in a number of ways; Irritation of the liquid phase by the ultrasonic energy results in the formation of extremely strong liquid jets that can easily penetrate to the deep pore sections [7]. Further, these liquid jets can scavenge and separate ultra-fine particles smearing and/or coating surfaces of larger entities [7]. The penetration of the ultrasonic waves into deep pore sections relies on the corona discharge or thermal heating during bubble-fragmentation or collapse of the bubbles [8]. This action provides mobility to the localized particles in the pores or voids, leading their redistribution within the flotation pulp as free-entities. This fosters better liberation amongst the organic-rich particles and inorganic entities, eventually leading to a more effective separation by flotation. In addition, the ultrasonic action is a stronger effect than mechanical agitation in flotation. Through ultrasonication, the interparticular attraction between ultrafine, surfacecoating inorganic particles and the coated organic-rich particles could be more easily and/or effectively overcome. This obviously contributes to the dispersion phenomenon, resulting better removal of the inorganic gangue through the froth phase in reverse flotation. Above 50\% ultrasonication power and 15 minutes of pre-treatment, the increase in the ash of the cleaned oil shale product implies loss of floatability of the inorganic particles. This could be attributed to the surface and morphological deformations at high ultrasonic power levels, as reported by Feng and Aldrich [9]. Feng and Aldrich found that excess ultrasonication generated surface defects and changed a smooth surface morphology into a relatively rough form, in a study on the effect of ultrasonication in the floatability of talc. The surface defects are likely to act as potential sites for water adsorption, reducing the floatability of the inorganic particles.

\subsection{Assessment of Ultrasonic-Aided Flotation by XRD and SEM}

XRD patterns of the flotation concentrate after ultrasonic pre-treatment $(11.82 \%$ ash $)$ at the favorable ultrasonication conditions (50\% ultrasonic power level, 15 minutes ultrasonication), flotation concentrate obtained at optimum flotation conditions (16.82\% ash) and raw oil shale (34.76\% ash) are presented given in Figures 2.a-c. The amorphous organic matter $\left(5^{0}-29^{0}\right)$ of the optimum flotation concentrate is comparatively more extensive compared to the raw oil shale (Figure 2 .a \& b). This shows the contribution of the cleaning on the organic content of the concentrate. After cleaning at optimum conditions, calcite and dolomite decreased (Figure 2.a \& b). Effetive rejection of pyrite was also seen. Few carbonate and pyrite peaks in the XRD pattern were due to the remaining inorganic matter in the concentrate. This might be due to either interlocked particles within the organic entities or non-liberated inorganic associations with the organic-rich particles. The strong physical attachment between carbonaceous gangue and organic particles after fine grinding would be another reason for the remaining calcite and dolomite in the cleaned oil shale product, as observed by Jeong and Kobylinski [10] for the 
Green River oil shale. After flotation with ultrasonic pre-treatment, dolomite and calcite in the concentrate further decreased, but no remarkable change in the extent of pyrite was seen (Figures $2 . b \&$ c). This implies that, pyrite bearing entities were not located in pores and/or void spaces and pyrite was removed to the possible extent through the optimum flotation conditions without ultrasonic pre-treatment. The further relative increase in the organic content of the cleaned oil shale through flotation with utrasonic pre-treatment, should be noted, as revealed by the increase in the overall intensity of the amorphous organic matter region (Figures 2.b \& c). The SEM images of the raw oil shale and the cleaned oil shale product after ultrasonic-aided flotation are presented in Figures $1 \& 6$. The carbonaceous gangue are recognized with lighter tones and occur as finer particles. The inorganic particulates as attached entities or as coatings or smearings on the surfaces of organic-rich particles are noteworthy. This was encountered as an obstacle against cleaning performance. After ultrasonic pre-treatment followed by flotation, the amount of the inorganic particles on larger organic-rich particles is much less. Also, the organic-rich particle surfaces are apparently cleaner (Figure 6), as compared to the SEM images of the raw oil shale (Figure 1). Hence, SEM images of the cleaned oil shale product obtained by ultrasonic-aided flotation show that ultrasonic pre-treatment was successful in enhancing interparticle detachment and in the removal of surface coatings. This confirms better separation of inorganic entities through an ultrasonic-aided flotation process.

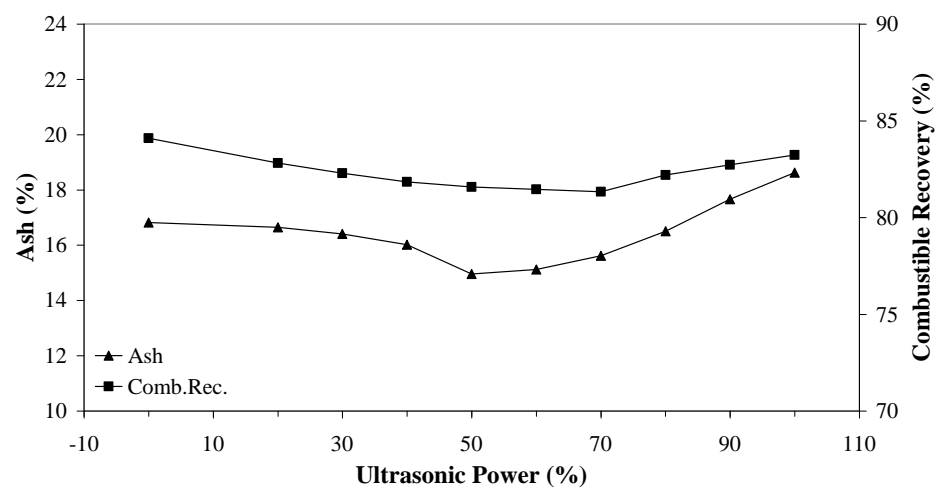

Fig: 4: Flotation of Oil Shale after Ultrasonic Pre-Treatment at Different Power Levels.

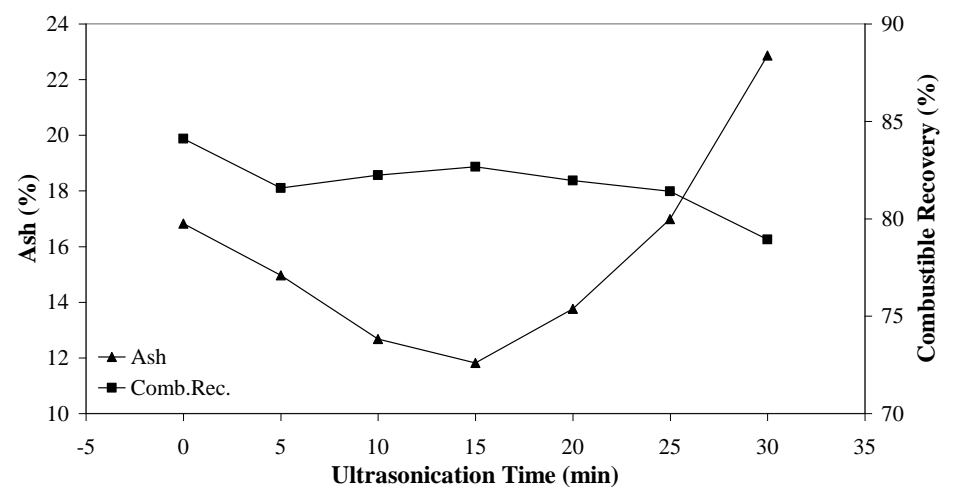

Fig. 5: Flotation of Oil Shale after Ultrasonic Pre-Treatment for Different Duration. 


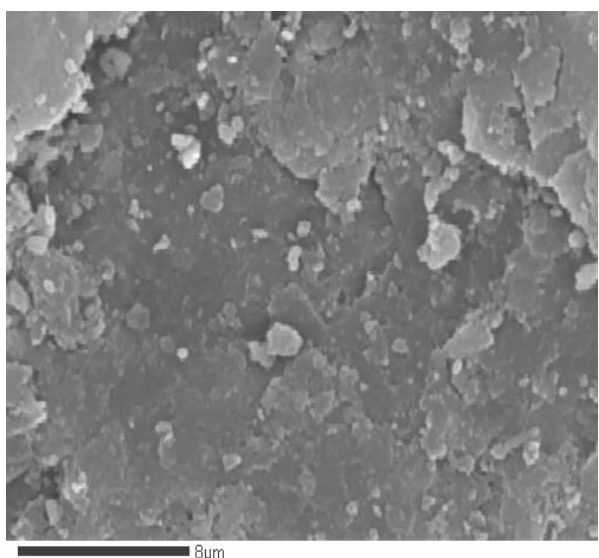

(a)

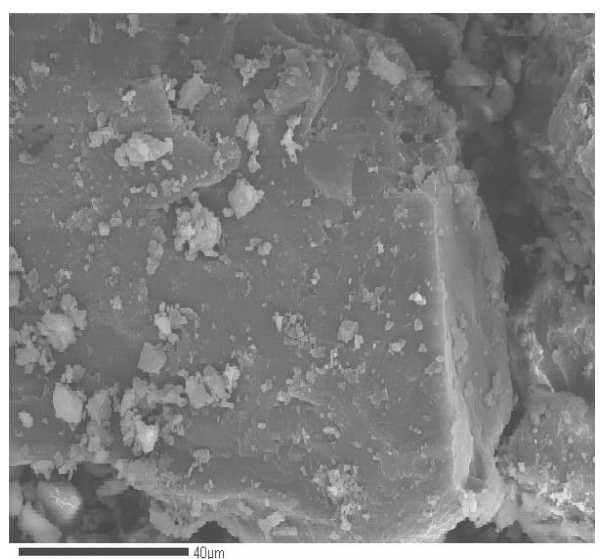

(c)

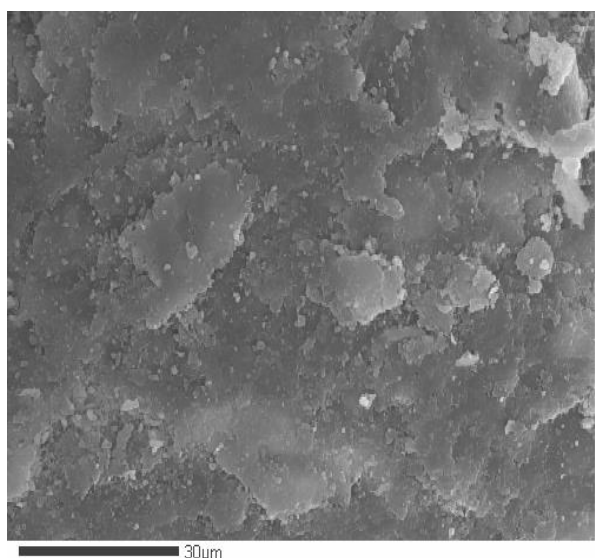

(b)

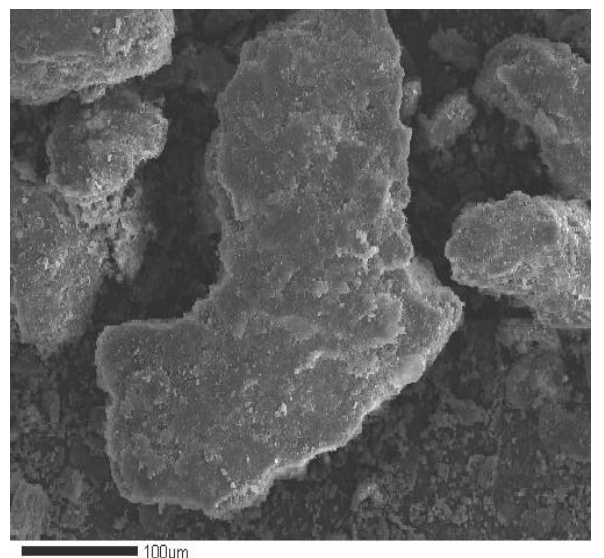

(d)

Fig. 6: Typical SEM Images of Cleaned Oil Shale Product Obtained by Ultrasonic-Aided Flotation.

\section{Conclusion}

Ultrasonic-aided flotation proved to be effective in increasing the performance of separation between the targeted particles and the undesired inorganic gangue, particularly when the gangue entities are ultra-fine and occur as fillings in voids/pores or when they coat and/or smear the surfaces of larger particles. If used properly, ultrasonication provides mobility to or causes detachment of ultra-fine particles. This contributes to the liberation between gangue and valuable entities. It also enhances the dispersion between particles in the flotation pulp. Yet, it should be noted that ultrasonic treatment can be useful up to a certain ultrasonic power level and treatment time. These parameters are critical and should be optimized - excess ultrasonication may easily lead to adverse consequences such as disintegration of particles coupled with slime formation and/or disturbance of particle morphology coupled with loss of floatability.

\section{References}

[1] C. Aldrich, D. Feng, "Effect of ultrasonic preconditioning of pulp on the flotation of sulphide ores," Miner Eng., vol. 12, no. 6, pp. 701-707, 1999.

[2] A. D. Farmer, A. F. Collings, G. J. Jameson, "Effect of ultrasound on surface cleaning of silica particles," Int J Miner Process., vol. 60, pp. 101-102, 2000.

[3] E. Riera-Franco de Sarabia, E. Gallego-Juarez, G. Rodriguez-Corral, L. Elvira-Segura, I. Gonzalez-Gomez, "Application of high-power ultrasound to enhance fluid/solid particle separation processes," Ultrasonics, vol. 38, pp. 642-646, 2000.

[4] M. C. Smythe, R. J. Wakeman, "The use of ultrasonic fields as a filtration and dewatering aid," Ultrasonics, vol. 38, pp. 657-661, 2000. 
[5] H. Kyllönen, P. Pirkonen, V. Hintikka, P. Parvinen, A. Grönroos, H. Sekki, "Ultrasonically aided mineral processing technique for remediation of soil contaminated by heavy metals," Ultrason Sonochem., vol. 11, pp. 211-216, 2004.

[6] N. E. Altun, "Beneficiation of Himmetoğlu and Beypazarı Oil Shales by Flotation and Their Thermal Characterization as an Energy Source," Ph.D. Thesis, METU Institute of Natural and Applied Sciences, Ankara, Turkey, p. 370, 2006.

[7] T. Mason, P. Lorimer, Sonochemistry: Theory, applications and use of ultrasound in chemistry. Ellis Horwood Limited, Chicester, 1998.

[8] P. R. Birkin, S. Silva-Martinez, "A study on the effect of ultrasound on electrochemical phenomena," Ultrason Chem., vol. 4, pp. 121-122, 1997.

[9] D. Feng, C. Aldrich, "Effect of particle size on the flotation performance of complex sulphide ores," Miner Eng., vol. 12, no. 7, pp. 721-731, 2004.

[10] K. M. Jeong, T. P. Kobylinski, "Organic-mineral matter interactions in Green River oil shale," American Chemical Society, Division of Fuel Chemistry Preprints, vol. 28, no. 3, pp. 209-214, 1983. 